\title{
Fundo de participação dos municípios e o desenvolvimento: uma análise dos municípios de pequeno porte do Brasil ${ }^{1}$
}

\section{Municipal participation fund and development: an analysis of small municipalities in Brazil}

\author{
Augusta Pelinski Raiher \\ Isabela Sens Fadel Gobbo** \\ Thais Sanson Sene ${ }^{\star \star \star}$
}

\begin{abstract}
Resumo: Este estudo tem como objetivo analisar a correlação entre o Fundo de Participação dos Municípios (FPM) e o desenvolvimento socioeconômico, mensurado pelo Índice Firjan de Desenvolvimento Municipal (IFDM), por meio da comparação dos dados de 2013 e de 2016 dos municípios brasileiros de pequeno porte. Para tanto, foram utilizados os dados FINBRA (Finanças do Brasil) e do Índice Firjan, mensurando a dependência dos municípios com relação aos repasses do FPM e sua correlação com o Índice Firjan de Desenvolvimento Municipal. Como corolário, identificou-se a importância do FPM para a composição da integralidade das receitas dos municípios de pequeno porte, principalmente para os municípios de menor desenvolvimento. Ademais, diferentemente do que se constatou nas demais regiões do país, no Norte e no Nordeste existe uma correlação positiva entre o desenvolvimento dos municípios e a dependência ao FPM.

Palavras-chave: Desenvolvimento; Fundo de Participação dos Municípios; municípios de pequeno porte.
\end{abstract}

\footnotetext{
${ }^{1}$ Uma versão preliminar deste texto foi apresentada no "III SIMPÓSIO INTERNACIONAL INTERDISCIPLINAR EM CIÊNCIAS SOCIAIS APLICADAS: Democracia e direitos humanos" realizado em Ponta Grossa- PR, entre 11 a 13 de setembro de 2019, sendo indicado pelo evento para compor este volume especial da Emancipação.

* Doutora em Economia pela Universidade Federal do Rio Grande do Sul. Professora do Programa de Pós-Graduação em Economia, do Programa de Pós-Graduação em Ciências Sociais e do departamento de economia da Universidade Estadual de Ponta Grossa. Bolsista Produtividade CNPQ.

** Doutoranda no Programa de Pós-Graduação em Ciências Sociais Aplicadas na Universidade Estadual de Ponta Grossa. Bacharel em Direito e Mestre em Ciências Sociais Aplicadas pela Universidade Estadual de Ponta Grossa. E-mail: isabelaf. gobbo@gmail.com.

${ }^{* * *}$ Mestre em Ciências Sociais Aplicadas pela Universidade Estadual de Ponta Grossa. Bacharel em Direito pela Universidade Estadual de Ponta Grossa. Email: thais.ssene@gmail.com
} 


\begin{abstract}
The objective of this study is to analyze the correlation between the Municipal Participation Fund (FPM) and socioeconomic development, as measured by Firjan Municipal Development Index (IFDM), by comparing the data for 2013 and 2016 for small Brazilian municipalities. For that, FINBRA (Finance of Brazil) and Firjan Index data were used, measuring the dependence of the municipalities in relation to the transfers of the FPM and their correlation with the Firjan Index. As a corollary, the importance of the FPM was identified for the composition of the integrality of revenues of small municipalities, especially for the less developed municipalities. Moreover, unlike the other regions, in the North and Northeast there is a positive correlation between development and dependence on FPM.
\end{abstract}

KeyWords: Development, Municipal Participation Fund, small municipalities.

Recebido em 19/09/2020. Aceito em 26/08/2020

\title{
Introdução
}

O aumento das responsabilidades municipais frente as necessidades básicas dos cidadãos, ao longo do tempo, passou a exigir dos municípios a ampliação de seus recursos para atender as mais variadas demandas em busca de melhores condições de bem-estar para aqueles que nestes espaços vivem. A tributação, mecanismo essencial de finalidade arrecadatória, sempre foi apontada como uma solução, porém a desigualdade horizontal e vertical ${ }^{2}$ de receita entre os entes federados precisava ser contornada para suprir as carências e, assim, o desenvolvimento dos municípios seria alcançado.

Nessa dinâmica, o acesso às receitas se tornaria mais igualitário e em maior conformidade com a distribuição de deveres estatais. E para isso, o Fundo de Participação dos Municípios (FPM) foi criado em 1965, por meio da Emenda Constitucional (EC) ํo 18, feita à Constituição Federal de 1946. Sua regulamentação se deu pelo Código Tributário Nacional (CTN - Lei 5.172, de 25 de outubro de 1966) e sua distribuição foi iniciada em 1967. Atualmente, após diversas normativas, este fundo tem por objetivo a transferência de receitas da União para os municípios, baseado na população, no inverso da renda per capita e na classificação destes em municípios do interior, da capital e de reserva. A partir de 2016, o FPM passou a responder por $24,5 \%$ da arrecadação líquida do Imposto de Renda (IR) e do Imposto sobre Produtos Industrializados (IPI) (ORAIR; ALENCAR, 2010)

O incremento do FPM nas receitas totais dos municípios apresenta-se de forma variável, dependendo dos critérios de sua distribuição, da transferência de outros fundos, e da capacidade de arrecadação própria de cada município. Sobre este último tópico, os médios e os grandes municípios são os que possuem maior capacidade para elevar sua arrecadação própria por meio dos impostos de sua competência (BOVO, 2001).

\footnotetext{
${ }^{2}$ A desigualdade vertical é referente aos diferentes níveis de governo, e a horizontal tem a ver com entes de mesmo nível.
} 
Nesse sentido, teoricamente, os de menor porte são os que mais dependem do que é repassado pelo FPM para serem agentes impulsionadores de seu próprio desenvolvimento. Esta dependência revela a hipótese de que se o aumento das transferências aos municípios é crescente conforme o aumento ou não da população, a maneira de fortalecer os municípios e diminuir essa dependência se dá via elevação da arrecadação própria.

Assim, é possível verificar a relação entre o FPM e o desenvolvimento, pois se o aumento do bolo da arrecadação representa menor dependência do fundo, em tese, o município com maior arrecadação própria teria mais recursos para investimento e desenvolvimento, levando à seguinte relação hipotética: quanto maior a dependência do FPM, menor o desenvolvimento/ investimento; quanto menor a dependência, maior a arrecadação própria e maiores investimentos e desenvolvimento.

Neste sentido, este trabalho tem como principal objetivo identificar a associação existente entre os repasses do FPM e desenvolvimento nos municípios de pequeno porte do Brasil. Fixou-se a análise nos municípios de pequenos exatamente por serem os mais vulneráveis na formação de suas receitas próprias, com um nível de dependência elevado do FPM na composição de suas receitas.

Metodologicamente, essa pesquisa se caracteriza como descritiva, compondo-se de uma pesquisa quantitativa. Para análise dos dados, foram considerados os municípios de pequeno porte como todos os que tinham população inferior a 20 mil habitantes em 2013 (MENDONÇA et al., 2016). Na análise do desenvolvimento de cada município, utilizou-se como proxy o Índice Firjan, e os montantes do FPM e das outras receitas dos municípios foram coletadas da FINBRA (Finanças do Brasil). Importante enfatizar que antes de se efetivar a correlação existente entre o FPM e o desenvolvimento de cada município, foi calculado a dependência dos municípios brasileiros em relação aos repasses do FPM, seguindo a metodologia de Passos e Nascimento (2018), mensurada pela divisão entre a receita do FPM e a Receita Corrente municipal, focando a análise entre os anos de 2013 e 2016.

\section{Fundo de Participação dos Municípios: implementação, objetivos e sua relação teórica com o desenvolvimento}

A discussão e reflexão acerca do desenvolvimento socioeconômico dos municípios brasileiros de pequeno porte perpassa necessariamente pela análise e compreensão mais acurada do FPM, seu processo de implementação, as bases que o sustentam e seus objetivos para, assim, poder estabelecer sua relação com o desenvolvimento.

Desse modo, neste primeiro momento será realizada a contextualização histórica do FPM, sua construção e evolução no ordenamento jurídico brasileiro, principalmente com relação aos municípios de pequeno porte. Na sequência, serão discutidos pontos importantes para entender a atual forma de estado federado do Brasil e as estratégias de desenvolvimento pós CF/88, com foco no sistema de transferência de receitas tributárias. Por último, serão estabelecidas as relações teóricas entre o modelo de transferências de receita via FPM e o desenvolvimento socioeconômico, de modo a permitir a posterior análise da relação de dependência dos municípios brasileiros de pequeno porte ao FPM, buscando aferir o grau de impacto do fundo na arrecadação total e no desenvolvimento socioeconômico destes municípios. 


\section{FPM: histórico/contextualização}

Como já explanado, a primeira distribuição do FPM se deu no ano de 1967, após sua regulamentação pelo CTN em 1966. Este período foi logo após o início do regime militar, no qual ocorreu uma grande centralização fiscal, que resultou em um aumento de $11 \%$ das receitas da União frente a perda de $12 \%$ das receitas dos estados e a pequena alteração nas receitas dos municípios entre os anos de 1965 e 1974 (ABRUCIO; COUTO, 1996). Com o passar do tempo, este modelo foi sendo modificado, até chegar em sua mudança mais emblemática na $\mathrm{CF} / 88$, resultado das dificuldades econômicas dos anos de 1980, da fragilização do Estado, o que também teve papel nas desarticulações finais do regime vigente até 1985 (SALLUM JR.; KUGELMAS, 1991).

Ao analisar as alterações nas normas constitucionais referentes ao FPM, Coelho (2007) aponta para as mudanças quanto ao valor repassado, às regras de aplicação destes recursos e de distribuição, determinadas pela conjuntura. Mesmo após uma centralização fiscal que ocorreu no regime militar, a partilha das receitas (espinha dorsal do pacto federativo) não foi revogada, ainda que tenha sido mais moderada (MENDES; MIRANDA; COSSIO, 2008).

Quando criado pela EC nº 18/1965, no seu artigo 21, o FPM era composto por $10 \%$ da receita do IR e IPI, e 50\% de seus recursos eram vinculados a despesas de capital, de aplicação regulamentada por lei a partir da Constituição Federal de 1967. No período mais autoritário do regime, a EC $\mathrm{n}^{\circ} 1$ de 1969 modificou consideravelmente o percentual de participação dos Fundos, o que reduziu o FPM a 5\%, retirando sua vinculação, mas impondo aos municípios uma série de questões para entregá-lo, como a aprovação prévia dos programas de aplicação dos recursos (COELHO, 2007). A EC nº 5 de 1975 ampliou o percentual destinado ao Fundo gradualmente. Apenas em 1980, com a Emenda Constitucional no 17 , as receitas destinadas a ele alcançaram um patamar maior do que o da época de sua criação, atingindo $11 \%$, além de terem sido retiradas algumas das dificuldades para sua entrega, passando a ser sua aplicação regulamentada por lei federal. Neste período, os recursos destinados ao fundo foram ampliados, passando a 16\% com a EC nº 23 de 1983, até chegar a 17\% pela EC ํㅡㄴ 27 de 1985, com a obrigatoriedade de vinculação de $6 \%$ para programas da saúde.

Com a CF $/ 88$, os repasses aumentaram para $20 \%$ destinados ao FPM, chegando a $22,5 \% \mathrm{em}$ 1993. No ano de 2007, a EC n² 55 possibilitou uma ampliação de $1 \%$ neste recurso, e em 2014, com a EC n 84 , o FPM passou a ser 24,5\% da arrecadação líquida de IR e IPI. Sobre a vedação ao acesso ou a vinculação da destinação, ambas passaram a ser constitucionalmente proibidas, conforme o artigo $160 \mathrm{da} \mathrm{CF} / 88$. O fundo passou a ser uma transferência do tipo incondicional, que não exige do governo receptor qualquer obrigação de aplicação dos recursos em despesas específicas e não cobra resultados (MENDES; MIRANDA; COSSIO, 2008). A partir disso, observa-se que o movimento de democratização possibilitou o aumento do volume de recursos destinados ao FPM, bem como seu menor controle por parte da União (COELHO, 2007).

Sobre os critérios de distribuição do Fundo, o CTN passou a prevê-los no seu artigo 91, o qual trazia como único critério o número de habitantes do município. Em 1967, pelo Ato Complementar $n^{\circ} 35$, o FPM foi dividido entre municípios do interior e capitais, sendo destinados $90 \%$ e 10\% dele, respectivamente. Outra subdivisão foi feita em 1981, por meio do Decreto Lei $n^{\circ}$ 1.881 , que determinou o percentual de 3,6\% destinado aos municípios com mais de 156.216 habitantes, passando o fundo do interior a 86,4\%. Com a Lei Complementar nº 91 de 1997, o número de habitantes destes municípios de reserva passou a ser 142.633.

Após a CF $/ 88$, as alterações foram casuísticas, devidas essencialmente pela mobilização dos municípios que teriam perdas na receita pela migração populacional (COELHO, 2007). Ressaltase que, desde que o FPM foi dividido, o inverso da renda per capita do ente federado passou a 
ser critério tanto para os municípios que são capitais quanto para os de reserva, conjuntamente com o critério populacional, situação que não ocorre para os municípios do interior que mantém somente o número de habitantes como regra (COELHO, 2007). No entanto, nos municípios do interior, a participação de cada um no total do fundo é distribuída em faixas populacionais, o que faz com que ela não seja perfeitamente linear (COELHO, 2007).

Além disso, antes de realizar a distribuição conforme as faixas, a participação de cada estado é delimitada e estabelecida anualmente pelas normativas do Tribunal de Contas da União (TCU), baseado tanto na população quanto no inverso da renda domiciliar per capita, conforme a Lei Complementar nำ62/1989. Tal questão permite afirmar que mesmo que existam municípios de população na mesma faixa, pode haver variações de estado para estado quanto aos recursos transferidos. Diante desses critérios, pode-se observar que os coeficientes aplicados beneficiam os municípios de pequeno porte frente aos de médio e grande porte se analisar o FPM per capita (FARINA; GOUVÊA; VARELA, 2007), e, também, por não existir outros critérios mais dinâmicos, como seria o índice de Desenvolvimento Humano Municipal (IDHM) ou o Índice Firjan, entretanto, distorções podem ocorrer. Estas situações podem ser mais perceptíveis num mesmo estado, mas podem ocorrer na comparação de municípios de estados diferentes, quando um deles, de maior IDHM ou Índice Firjan, pode receber maiores repasses do que outro de mesma população, mas com menores índices.

Com o exposto, nota-se que o FPM como se tem hoje é fruto da conjuntura, das disputas travadas entre aqueles que se beneficiam por ele, o que é salientado pelo seu aumento ao longo do tempo, e pela maior autonomia conferida aos municípios na aplicação dos recursos. Analisar a dependência dos municípios a ele e sua correlação ao desenvolvimento socioeconômico poderá trazer novos olhares para sua maior eficácia na diminuição das desigualdades vertical e horizontal, que não são apenas populacional, na renda per capita ou na receita.

\section{Federalismo e desenvolvimento}

A CF/88 inaugurou uma nova ordem institucional e jurídica no país, modificando profundamente a estrutura organizacional político-administrativa do Estado brasileiro ao adotar um modelo único de federalismo ${ }^{3}$. Influenciado pelas circunstâncias que resultaram na redemocratização do Brasil, aliado à mobilização dos movimentos sociais pela descentralização do poder de decisão, principalmente após décadas de regime ditatorial, e visando fortalecer os espaços de poder local, o município foi elevado à categoria de ente federativo dotado de autonomia política, legislativa, administrativa e financeira, equiparando-se hierarquicamente à União, aos Estados e ao Distrito Federal (art. 18, CF/88).

Sob a perspectiva política, o município foi compreendido como importante agente dentro do processo de redemocratização das estruturas de poder, de modo que possibilitou a transferência das políticas sociais até as esferas locais de governo, oportunizando melhor acesso a direitos e controle social das políticas (ARRETCHE, 2000; HOFMEISTER, 2001; FLEURY, 2006).

Necessário destacar que a descentralização das políticas emergiu em um cenário em que o modelo de desenvolvimento vigente desde a década de 1950, isto é, o modelo de industrialização

\footnotetext{
${ }^{3}$ A forma de Estado Federal no Brasil data da proclamação da República, em 1889, sendo mantido nas constituições posteriores, inclusive na Constituição de 1967 e sua emenda 1/69, embora tenha sido apenas de forma nominal. A Constituição Federal de 1988, então, manteve a forma federativa de estado, inovando quanto à inserção dos municípios como entes federativos (N.A).
} 
por substituição de importações, se esgotava sem que o governo federal tivesse as condições necessárias para conduzir o desenvolvimento nacional (HERMANN, 2011). Assim, diante da crise fiscal que atingiu a economia brasileira, com a descentralização e a repartição de competências, prosperou a ideia de que os governos regionais e municipais atuariam como instrumentos políticos de desenvolvimento sob uma perspectiva mais territorial do que nacional.

Neste período, elevaram-se as transferências de recursos da União para os municípios, fortalecendo-os enquanto entes federativos, o que também pode ser observado no histórico do FPM. Todavia, a nova organização que proporcionou inicialmente o fortalecimento dos municípios mediante o aumento de transferências intergovernamentais para o aporte das políticas, suscitou reações por parte da União que fragilizaram a esfera da autonomia financeira, uma vez que o ente federal sentiu uma grande redução orçamentária (SANTOS, 2008; ARRETCHE, 2005). Desse modo, num contexto de crise econômica nacional e, frente a perda de recursos da União, aprovou-se uma série de propostas de emenda à Constituição que acabaram por limitar sobremaneira a autonomia financeira dos municípios a partir da década de 1990 (AFFONSO, 2004; RESENDE, 2007; SANTOS, 2011). Assim, instala-se a tensão entre o acúmulo de atribuições e a capacidade de financiá-las, desvelando as relações intergovernamentais fomentadas pelo sistema constitucional de repartição de competências, que envolve o sistema de arrecadação e transferências de recursos.

Nesse sentido, de acordo com a CF/88, a receita tributária dos municípios compreende a arrecadação de receitas próprias (artigo 156), advindas da atividade direta do ente público, e impróprias (artigo 158), oriundas das transferências constitucionais e voluntárias da União e dos estados, através de fundos de participação ou de impostos que são de competência dos demais entes federados. Dessa lógica de "estruturação das receitas x transferência de recursos" se extrai que há maior autonomia financeira na medida em que o município tem maior capacidade de arrecadação própria. Nesse sentido, Castro (2006, p. 239) afirma que possuir autonomia financeira significa ter a capacidade de "[...] instituir e arrecadar os tributos da sua competência, bem como aplicar suas rendas, sem prejuízo da obrigatoriedade de prestar contas e publicar balancetes nos prazos fixados em lei".

Com o exposto, é possível compreender que apenas pela geração própria de receita, realizada com critérios estabelecidos pelos municípios, haverá uma maior capacidade destes em definir seu grau de dependência ao FPM. A composição do fundo é definida pela arrecadação da União e pode variar ano após ano, bem como a dos municípios, o que pode estar ligado a diversos fatores. E por isso, pela autonomia conferida a eles sobre os mais variados critérios que dão mais eficiência a sua arrecadação própria, pode-se dizer que a responsabilidade maior pela dependência municipal ao fundo é destes. Outra questão que merece destaque é referente ao fato de que quanto mais se arrecada, indiferentemente da fonte, maior é a possibilidade de se efetivar políticas públicas que viabilizem uma melhora do bem-estar. Ou seja, com o que se tem hoje sobre a distribuição do FPM, a hipótese de que quanto menor a dependência ao fundo, maior é a arrecadação própria e, consequentemente, maior o desenvolvimento socioeconômico, é reafirmada.

\section{O Fundo de Participação dos Municípios e o desenvolvimento socioeconômico}

O histórico legislativo do FPM demonstra que sua relevância foi majorada no decorrer do tempo, até se tornar uma importante fonte de renda não vinculada para todos os municípios, já 
que não há exclusão. Disso, revela-se o caráter redistributivo do fundo. Sua forma de distribuição, a partir de seus critérios, pode conferir maior ou menor relevância deste para uma equalização vertical e horizontal, tanto das capacidades quanto das necessidades fiscais (ORAIR; ALENCAR, 2010). E nisso se aponta que o fundo deve ser um mecanismo cujo objetivo é o de suprir a incapacidade de geração de receita própria dos municípios no que pese a União, o que não é o caso de todos.

O novo pacto federativo, aprovado pela CF/88, trouxe mudanças significativas para as responsabilidades dos municípios frente aos cidadãos. Independentemente da incapacidade técnica ou dos fatores econômicos que dificultam uma maior arrecadação própria, todo município demandará de recursos para cumprir com seus deveres constitucionais. Quando essa receita não é garantida por ação direta municipal, a dependência pelo FPM aumenta. Os recursos disponíveis pelo FPM são fixados conforme as regras de distribuição que envolve principalmente o número de habitantes dos municípios, critério de pouca variação temporal. Ou seja, se todo ano a receita líquida do IPI e do IR for a mesma, e o município não crescer de forma exorbitante em sua população, consequentemente ele receberá o mesmo valor do FPM, o que faz com que a dependência dos municípios ao montante que recebem do fundo possa ser relacionada pela maior ou menor capacidade que estes municípios se esforçam para aumentar sua arrecadação própria.

Todo o referencial estudado revelou a importância da não dependência ao fundo para uma maior arrecadação própria e, assim, um maior desenvolvimento por meio da implementação de políticas públicas. Mas para entender a correlação existente entre o FPM e o desenvolvimento, o inverso da hipótese precisa ser averiguado. Como já asseverado, os recursos do fundo possuem caráter não vinculado, ou seja, trata-se de recurso disponível para livre aplicação e sua transferência é essencial para municípios que não possuem condições de realizar um maior esforço arrecadatório.

A baixa correlação entre tamanho da população e Índice de Desenvolvimento Humano (IDH) dos municípios faz com que correlação entre o FPM per capita e o IDH municipal também seja, teoricamente, inexistente (MENDES; MIRANDA; COSSIO, 2008). Tal situação explica que o fundo por si só não é o que gerará o desenvolvimento. Além disso, desde 1991, a principal fonte de arrecadação própria dos municípios é o Imposto sobre Serviços de Qualquer Natureza (ISS), o qual tende a encontrar uma maior base tributária nas localidades economicamente mais dinâmicas, ou seja, os municípios mais pobres acabam por não conseguir essa importante parcela de recurso (ABRUCIO; COUTO, 1996). Tem-se, então, que o FPM tende a representar um grande percentual de toda a receita principalmente dos municípios mais pobres, e é com este recurso que se conseguirá atender as demandas da sociedade e gerar desenvolvimento.

Com o exposto, é fato que todo recurso, seja por arrecadação própria ou por transferência será muito bem vindo para que os municípios consigam efetivar suas políticas e gerar seu desenvolvimento. Quanto maior for a transferência via FPM, maiores serão as possibilidades de se garantir tais consequências diretas da arrecadação por sua aplicação. Mas para os municípios mais pobres e de pequeno porte o FPM tem muito mais valor, seja pelos critérios que privilegiam estes, ou porque as dificuldades de se dinamizar a economia são maiores.

\section{FPM e o Desenvolvimento: evidências empíricas para os municípios de pequeno porte do Brasil}

Com o passar dos anos, o incremento das transferências dos recursos do FPM reafirmou o papel deste como uma importante fonte de renda aos municípios, especialmente para os de 
pequeno porte, apontando a possibilidade de equilíbrio das receitas municipais àqueles municípios com baixa capacidade de arrecadação própria e, assim, permitindo melhor implementação de políticas públicas e desenvolvimento municipal. Tal relação indica, em princípio, uma relação negativa entre FPM e o desenvolvimento do município. Contudo, sem que haja o fortalecimento das possibilidades de arrecadação própria para os municípios de pequeno porte, o fundo de forma isolada não será o responsável pela promoção de desenvolvimento, o que pode ser verificado nos dados que seguem.

Ao analisar o percentual de transferência do FPM para os grupos de municípios e o índice de desenvolvimento, observa-se que, de todo o montante transferido para os municípios do Brasil, 78\% foi para os que apresentavam mais de 20 mil habitantes. Ou seja, apenas uma pequena quantidade de valores foi para os municípios de pequeno porte, os quais representavam $69 \%$ dos municípios brasileiros e detinham $16 \%$ da população.

Os municípios de médio e grande porte, excetuando as capitais, têm maior tendência em ampliar sua densidade populacional, por se configurarem como áreas de atividade migratória e por apresentarem melhor dinamismo econômico em relação aos municípios de pequeno porte. De 2013 a 2014, os municípios que mais cresceram em número de habitantes foram os municípios de médio porte, compreendidos como aqueles que possuem população entre $100 \mathrm{mil}$ e $500 \mathrm{mil}$ habitantes (IBGE, 2014). Como o critério população tem elevada influência na distribuição do FPM, é possível justificar, assim, a elevação do repasse para os municípios com mais de 20 mil habitantes frente aos de pequeno porte.

Além disso, ao observar que os municípios de mais de 20 mil habitantes, em sua integralidade, tiveram um aumento do percentual do repasse do FPM e uma elevação do índice de desenvolvimento ao longo do tempo, tem-se uma relação positiva, diferentemente do que o referencial teórico aponta. Nos municípios de pequeno porte, os dados sinalizam que a diminuição do percentual do fundo repassado a eles não resultou em alterações evidentes no desenvolvimento, o que permite afirmar que tal redução não trouxe consequências para o índice. Importante dizer que esta relação é diferente da existente entre a dependência dos municípios à transferência do FPM e o desenvolvimento, posto que, verifica-se na tabela 1 uma relação de disputa dos recursos do fundo, os quais foram repassados em menor quantidade para os municípios de pequeno porte no ano de 2016, frente a 2013.

Tabela 1: Percentual do FPM para cada grupo de municípios e IFDM médio - Por porte - 2013 e 2016

\begin{tabular}{l|l|l|l|l}
\hline População & FPM2016*(\%) & FPM 2013*(\%) & IFDM 2016** & IFDM 2013** \\
\hline Mais de $20 \mathrm{mil}$ & 78.3 & 78.2 & 0.69 & 0.68 \\
\hline Menos de $20 \mathrm{mil}$ & 21.7 & 21.8 & 0.66 & 0.66 \\
\hline
\end{tabular}

Fonte: *Finbra e **Firjan, com os dados organizados pela pesquisa.

Na sequência (Tabela 2), analisando o grau de dependência do FPM, percebe-se uma maior vulnerabilidade para os municípios de pequeno porte, dado que, em torno de $43 \%$ das receitas correntes destes municípios advém de transferências do FPM, enquanto que para os municípios maiores o repasse do fundo representa, na média, 26\% das suas receitas. Isso revela os desequilíbrios entre os municípios brasileiros e as desigualdades nas possibilidades de arrecadação própria, uma vez que, na média, os municípios menores recebem um percentual pequeno de todo o FPM do país (Tabela 1) e mesmo assim essa receita representa quase a metade da receita corrente desses municípios, indicando, por consequência, baixa capacidade de arrecadação própria. 
Outra questão observada é a ampliação da dependência ao longo do tempo de todos os portes de municípios, o que pode ser plausível pelo aumento do percentual da receita líquida do IR e do IPI em 1\% no ano de 2014 pela Emenda Constitucional no 84. Aumentou-se o bolo total, aumentou o repasse e, assim, a dependência dos municípios ao fundo, considerando que tudo o mais permaneceu constante. Ou/e, ainda, pode-se supor que houve também uma diminuição da receita corrente ao longo do tempo para todos os municípios, o que também possibilitaria um aumento da dependência.

Tabela 2: Dependência média do FPM por porte de município - 2013 e 2016

\begin{tabular}{l|l|l}
\hline & FPM/Receitas correntes 2016 & FPM/Receitas correntes 2013 \\
\hline Mais de $20 \mathrm{mil}$ & 0.267 & 0.258 \\
\hline Menos de $20 \mathrm{mil}$ & 0.435 & 0.427 \\
\hline
\end{tabular}

Fonte: *Finbra, com os dados organizados pela pesquisa.

Essa maior dependência é ratificada na Tabela 3, na qual se observa que 58\% dos municípios de pequeno porte detinham em 2016 uma dependência do FPM entre 40 a $70 \%$, percentual bem inferior ao obtido pelos municípios de maior porte: $11 \%$. No caso destes últimos, a relação entre FPM e receitas correntes ficou mais concentrada entre 10\% a 30\%, comprovando a menor vulnerabilidade orçamentária desses municípios.

O dinamismo econômico dos municípios maiores, que resulta em uma maior arrecadação de ISS, e também num maior repasse do Imposto sobre Circulação de Mercadorias e Serviços (ICMS), proveniente da devolução de $25 \%$ aos municípios de origem de sua arrecadação (segundo o artigo 158, inciso IV da CF/88), possibilita uma menor dependência aos recursos transferidos pelo fundo. Essa transferência do ICMS é a maior realizada aos municípios, ficando o FPM em segundo lugar, e seu caráter devolutivo pode ser destacado ao afirmar que os municípios de maior IDH foram os que tiveram maior repasse de ICMS no ano 2000, conforme Mendes, Miranda e Cossio (2008).

Tabela 3: Percentual de município considerando a sua dependência orçamentária (FPM/ receita corrente (RC)) - por porte de municípios - 2016 e 2013

\begin{tabular}{l|l|l|l|l}
\hline \multirow{2}{*}{ FPM/RC } & \multicolumn{2}{l}{ Pequeno porte } & \multicolumn{2}{l}{ Mais que 20 mil habitantes } \\
\cline { 2 - 5 } & FPM/RC 13 (\%) & FPM/RC 16 $\%)$ & FPM/RC 13 (\%) & FPM/RC 16(\%) \\
\hline 0 a 10\% & 0.7 & 1.3 & 8.2 & 7.7 \\
\hline 10 a $20 \%$ & 2.5 & 2.1 & 23.0 & 21.0 \\
\hline 20 a $30 \%$ & 12.0 & 10.5 & 32.2 & 32.2 \\
\hline 30 a $40 \%$ & 25.3 & 26.2 & 28.3 & 27.7 \\
\hline 40 a $50 \%$ & 32.1 & 30.1 & 7.7 & 10.0 \\
\hline 50 a $60 \%$ & 20.6 & 19.7 & 0.1 & 0.2 \\
\hline 60 a $70 \%$ & 6.2 & 7.8 & 0.1 & 0.2 \\
\hline 70 a $80 \%$ & 0.3 & 1.2 & 0.0 & 0.2 \\
\hline 80 a $90 \%$ & 0.1 & 0.4 & 0.3 & 0.1 \\
\hline 90 a $100 \%$ & 0.2 & 0.7 & 0.2 & 0.6 \\
\hline
\end{tabular}

Fonte: *Finbra, com os dados organizados pela pesquisa. 
Neste contexto, por apresentarem uma maior dependência, e concomitantemente, por deterem um nível de desenvolvimento menor, focou-se na relação existente entre a dependência das transferências do FPM e o Índice Firjan de Desenvolvimento Municipal nos municípios de pequeno porte.

Na tabela 4 subdividiram-se tais municípios por regiões do país. Observa-se que, em 2013, existia uma dependência grande dos municípios de pequeno porte do nordeste pelo FPM, em que, $45 \%$ tinham uma relação FPM/RC entre 40 a 50\%. Considerando uma relação FPM/RC acima de $50 \%$, a região que mais municípios detinham essa característica era a Sudeste, com 33\% de seus municípios, seguida pelo Nordeste (29\%), 25\% para o Norte, 22\% para o Sul e $17 \%$ para o Centro-Oeste. Ao mesmo tempo, as Regiões com maiores percentuais de municípios com $20 \%$ ou menos de relação FPM/RC foram o Centro-Oeste (8\%) e o Sudeste (5\%), seguida pelo Norte (4\%) Sul (2\%) e Nordeste(1\%).

Tabela 4: Percentual de município considerando a sua dependência orçamentária (FPM/ receita corrente (RC)) - municípios de pequeno porte por região- 2016 e 2013

\begin{tabular}{|c|c|c|c|c|c|c|c|c|c|c|}
\hline \multirow[b]{2}{*}{ FPM/RC (\%) } & \multicolumn{5}{|c|}{ FPM/RC 13} & \multicolumn{5}{|c|}{ FPM/RC 16} \\
\hline & Norte & Nordeste & Sudeste & Sul & $\begin{array}{l}\text { Centro } \\
\text { Oeste }\end{array}$ & Norte & Nordeste & Sudeste & Sul & $\begin{array}{l}\text { Centro } \\
\text { Oeste }\end{array}$ \\
\hline 0 a 10 & 0.79 & 0.70 & 0.89 & 0.44 & 1.19 & 0.00 & 2.45 & 0.80 & 0.11 & 3.21 \\
\hline 10 a 20 & 3.17 & 0.70 & 3.74 & 1.41 & 6.55 & 3.72 & 0.36 & 2.50 & 1.20 & 7.87 \\
\hline 20 a 30 & 18.25 & 2.46 & 16.67 & 13.38 & 20.54 & 19.01 & 2.54 & 11.25 & 12.17 & 23.32 \\
\hline 30 a 40 & 35.71 & 21.23 & 18.09 & 33.95 & 32.14 & 30.99 & 20.80 & 21.96 & 35.65 & 28.28 \\
\hline 40 a 50 & 16.67 & 45.26 & 27.63 & 28.94 & 22.32 & 21.90 & 40.69 & 26.25 & 28.48 & 18.95 \\
\hline 50 a 60 & 15.87 & 20.70 & 24.42 & 18.93 & 15.48 & 14.05 & 18.98 & 24.73 & 19.46 & 10.20 \\
\hline 60 a 70 & 8.33 & 7.63 & 8.47 & 2.83 & 1.49 & 9.09 & 9.81 & 10.71 & 2.72 & 4.66 \\
\hline 70 a 80 & 1.19 & 0.44 & 0.09 & 0.11 & 0.00 & 0.41 & 2.18 & 1.61 & 0.11 & 0.58 \\
\hline 80 a 90 & 0.00 & 0.18 & 0.00 & 0.00 & 0.30 & 0.00 & 0.73 & 0.09 & 0.00 & 1.46 \\
\hline 90 a 100 & 0.00 & 0.70 & 0.00 & 0.00 & 0.00 & 0.83 & 1.45 & 0.09 & 0.11 & 1.46 \\
\hline
\end{tabular}

Fonte: *Finbra, com os dados organizados pela pesquisa.

Assim, esses dados demonstram que os municípios de pequeno porte da região Nordeste eram os mais dependentes dessas transferências, e o Centro-Oeste tinha os municípios menos condicionados a esses repasses. Têm-se duas possíveis justificativas para esse fato: a alta população que o Nordeste detém (segunda região com maior concentração populacional) associada à baixa atividade produtiva quando comparado ao Sul/Sudeste/Centro-Oeste.

Com efeito, na Tabela 5 têm-se na população média os dados que ratificam essa inferência: por um lado, se constata uma densidade populacional maior dos municípios de pequeno porte de cada região, na qual se verifica a densidade maior no Nordeste. Na contramão, em se tratando de produção, avaliada pelo Produto Interno Bruto (PIB), observa-se que nessa região têm-se as menores médias municipais. Isso corrobora a inferência anterior, justificando a maior dependência dessa região pelo FPM para o PIB (Produto Interno Bruto) e para o PIB per capita.

Ao analisar o percentual repassado aos estados para a constituição do cálculo da transferência do FPM aos dos municípios do interior, conforme o anexo VI da Decisão Normativa $n^{\circ}$ 173/2019 do TCU, tem-se o seguinte: os estados do Centro-Oeste correspondem a 7,1271\%, do Sudoeste a $32,944 \%$, o Norte a $7,0692 \%$, o Sul a $18,7865 \%$ e o Nordeste a $34,732 \%$. Com isso, os 
próprios critérios distributivos explicam o porquê dessa maior dependência do FPM do Nordeste, decorrente da população mais densa e da menor atividade produtiva.

O Produto Interno Bruto (PIB) dos municípios com menos de 20 mil habitantes, no ano de 2013, representou menos de $10 \%$ do total, enquanto cerca de $70 \%$ foi gerado por municípios com mais de 100 mil habitantes.

Tabela 5: Média do PIB, da População e do PIB per capita - municípios de pequeno porte - regiões brasileiras

\begin{tabular}{l|l|l|l}
\hline Região & PIB(milhões de R\$) & População & PIB per capita (Mil R\$) \\
\hline Norte & 122882 & 9185 & 14 \\
\hline Nordeste & 85153 & 10080 & 9 \\
\hline Sudeste & 156693 & 8186 & 19 \\
\hline Sul & 187254 & 6913 & 28 \\
\hline Centro Oeste & 218397 & 7749 & 27 \\
\hline
\end{tabular}

Fonte: Ipeadata.

Olhando em termos de desenvolvimento desses municípios de pequeno porte, ocorreu uma saída dos níveis mais altos de desenvolvimento, caindo o percentual dos que tinham índices entre 0,80 a 0,90, e dos que tinham entre 0,70 a 0,80 (Tabela 6). Regionalmente, observa-se que apenas o Sul, o Sudeste e o Centro-Oeste tinham municípios com desenvolvimento acima de 0,80. Ademais, o Norte e Nordeste detinham $47 \%$ e $48 \%$, respectivamente, de municípios com índices considerados bons (entre 0,60 e 0,80 ), ao passo que as demais regiões tinham mais de $85 \%$ de seus municípios de porte pequeno nessa classificação.

Neste contexto, existe uma desigualdade entre esse grupo de município, com discrepâncias no que se refere ao desenvolvimento socioeconômico. Além disso, se somados os percentuais de municípios de pequeno porte com índices entre 0,60 e 0,80, e colocados em ordem das regiões que possuem mais para as que possuem menos municípios, o Centro-Oeste se encontra em primeiro lugar. Assim, o desenvolvimento mais elevado nesta região justifica uma maior possibilidade de se ter atividade produtiva passível de elevação da tributação própria ou de tributos que possam ser transferidos, o que se apresenta como uma motivação para a baixa dependência desta região na Tabela 4. 
Tabela 6: IFDM médio dos municípios de pequeno porte (\% de municípios em cada intervalo de IFDM) - 2013 e 2016

\begin{tabular}{|c|c|c|c|c|c|c|c|c|c|c|c|c|}
\hline \multirow[b]{2}{*}{ IFPM } & \multirow{2}{*}{$\begin{array}{l}2016 \\
\text { (\% de mun.) }\end{array}$} & \multirow{2}{*}{$\begin{array}{l}2013 \\
\text { (\% de mun.) }\end{array}$} & \multicolumn{5}{|c|}{2016 (\% de municípios) } & \multicolumn{5}{|c|}{2013 (\% de municípios) } \\
\hline & & & Norte & Nordeste & Sudeste & Sul & Centro Oeste & Norte & Nordeste & Sudeste & Sul & Centro Oeste \\
\hline 0,30 a 0,40 & 0.11 & 0.16 & 0.4 & 0.3 & 0.0 & 0.0 & 0.0 & 0.4 & 0.4 & 0.0 & 0.0 & 0.0 \\
\hline 0,40 a 0,50 & 3.78 & 6.04 & 14.4 & 8.9 & 0.2 & 0.0 & 0.9 & 17.6 & 15.2 & 0.4 & 0.0 & 1.4 \\
\hline 0,50 a 0,60 & 19.46 & 20.01 & 38.5 & 43.2 & 9.2 & 1.5 & 8.7 & 32.8 & 47.8 & 6.8 & 2.2 & 9.3 \\
\hline 0,60 a 0,70 & 41.72 & 34.14 & 42.0 & 44.1 & 44.9 & 32.8 & 47.4 & 45.0 & 33.5 & 34.6 & 28.1 & 42.9 \\
\hline 0,70 a 0,80 & 30.99 & 32.77 & 4.7 & 3.5 & 40.0 & 57.1 & 41.6 & 4.2 & 3.1 & 47.5 & 56.0 & 42.9 \\
\hline 0,80 a 0,90 & 3.94 & 6.85 & 0.0 & 0.0 & 5.7 & 8.6 & 1.5 & 0.0 & 0.1 & 10.8 & 13.7 & 3.5 \\
\hline
\end{tabular}

Fonte: Firjan, organizado pela pesquisa.

Os dados concentrados na tabela 6 fazem a primeira associação entre FPM e o desenvolvimento (IFDM). Observa-se que aqueles municípios com pouca dependência do FPM ( 0 a 10\%) estavam quase que 50\% com IFDM acima de 0,70; o mesmo cenário se verifica para uma dependência de até 40\%. A partir daí, a concentração maior dos municípios manteve-se com um IFDM entre 0,60 e 0,70, até chegar numa dependência elevada, entre 90 a 100\%, cujo IFDM da maioria ficou entre 0,50 e 0,60. Ou seja, conforme se elevou a dependência, a tendência era pela diminuição do IFDM da maioria dos municípios. Além dessa concentração maior em níveis de desenvolvimento menor, esses municípios com uma dependência maior (acima de 80\%) do FPM não conseguiram ter nenhum inserido em IFDM acima de 0,70, o que evidencia uma deterioração maior do bem-estar da população enquadrada nesse grupo.

Tais dados, ao demonstrarem que os municípios com melhor desenvolvimento são aqueles que possuem pouca ou nenhuma dependência do FPM, revelam que o referencial teórico, quando observa a integralidade dos municípios de pequeno porte, converge ao exposto. Existe, na Tabela 7, a visualização da relação negativa entre a dependência e o desenvolvimento.

Tabela 7: IFDM por grau de dependência do FPM (FPM/RC) - municípios de pequeno porte - 2016

\begin{tabular}{l|l|l|l|l|l|l}
\hline FPM/RC (\%) & \multicolumn{7}{|l}{ IFDM (\% de municípios por cada nível de dependência FPM/RC) } \\
\hline & 0,30 a 0,40 & 0,40 a 0,50 & 0,50 a 0,60 & 0,60 a 0,70 & 0,70 a 0,80 & 0,80 a 0,90 \\
\hline 0 a 10 & 0.0 & 0.0 & 17.9 & 35.7 & 39.3 & 7.1 \\
\hline 10 a 20 & 0.0 & 3.2 & 6.5 & 32.3 & 48.4 & 9.7 \\
\hline 20 a 30 & 0.0 & 3.4 & 7.8 & 27.5 & 50.6 & 10.7 \\
\hline 30 a 40 & 0.2 & 5.2 & 19.2 & 34.3 & 36.0 & 5.1 \\
\hline 40 a 50 & 0.1 & 3.9 & 23.1 & 46.9 & 24.1 & 1.9 \\
\hline 50 a 60 & 0.1 & 2.1 & 19.6 & 50.3 & 25.9 & 2.0 \\
\hline 60 a 70 & 0.0 & 1.8 & 22.4 & 52.2 & 22.8 & 0.9 \\
\hline 70 a 80 & 0.0 & 0.0 & 40.0 & 40.0 & 20.0 & 0.0 \\
\hline 80 a 90 & 0.0 & 0.0 & 33.3 & 66.7 & 0.0 & 0.0 \\
\hline 90 a 100 & 0.0 & 12.5 & 62.5 & 25.0 & 0.0 & 0.0 \\
\hline
\end{tabular}

Fonte: Finbra e Firjan, com dados organizados pela pesquisa.

Por fim, foi realizada uma correlação entre o grau de dependência e o IFDM de cada município de pequeno porte por região (Tabela 8), já que se observou diferenças importantes entre estas nas tabelas anteriores. Se fosse analisado apenas o Brasil como um todo, ter-se-ia uma associação negativa entre IFDM e FP/RC, a qual se tornou ainda mais forte no decorrer dos anos. Entretanto, ao fazer a correlação por região, obteve-se para o Sul, Sudeste e Centro-Oeste uma igual associação, ou seja, negativa. Contudo, para o Norte e Nordeste a correlação foi positiva, de maneira que, quando se eleva a dependência, tende-se a aumentar o desenvolvimento (e vice-versa).

Assim, exatamente no Nordeste, cuja dependência era a maior (Tabela 4), teve-se a maior relação positiva. A ampliação dos recursos transferidos via FPM, especificamente para esta região pode ser uma justificativa. Todavia, por se tratar da região historicamente mais pobre do país, outros programas de transferência de recursos federais, bem como políticas públicas específicas, foram realizadas na região (CARVALHO, 2018), tais como o Fundo Constitucional de Financiamento do Nordeste (1988) e o Fundo de Desenvolvimento do Nordeste (2001), destinados ao desenvolvimento socioeconômico regional, recursos esses que não entram nas receitas correntes municipais, mas que também podem ter sido responsáveis 
por gerar desenvolvimento nesta região. Além disso, novas políticas de coesão social, inauguradas pela CF/88 e guiadas pelo princípio da solidariedade regional contribuíram para impulsionar o desenvolvimento da região Nordeste acima da média nacional entre os anos 2000-2016, a exemplo dos 3\% da arrecadação do IR e do IPI destinados a programas de financiamento e estímulo do setor produtivo das regiões Norte, Nordeste e Centro-Oeste do país (artigo 159, inciso I, letra c da CF/88) (AMARAL FILHO,2012 apud CARVALHO 2018).

Percebe-se que naquelas regiões onde o desenvolvimento é maior (Tabela 8), a correlação entre o IFDM e o FPM/RC é inversa, o que ocorre na região Sul, Sudeste e Centro-Oeste. A maior facilidade de ampliar a arrecadação própria dessas regiões, decorrente do maior potencial de atividades produtivas capazes de serem tributadas (conforme visualizado na Tabela 6), explica o coeficiente negativo que se obteve, conseguindo elevar o desenvolvimento mesmo sem elevar o FPM.

Para além da análise já feita, os dados da Tabela 8 deixam nítido que, pelo alto grau de dependência existente entre os municípios que supostamente tem um menor grau de desenvolvimento (no Norte e Nordeste), o FPM é de extrema importância na geração do desenvolvimento destes, que são os municípios possivelmente mais pobres. Se o fundo não fosse repassado, ou não fosse maior para estes, o desenvolvimento atingido seria menor ao longo dos anos.

Tabela 8: Coeficiente de Correlação entre o IFDM e FPM/RC - municípios de pequeno porte - regiões do Brasil - 2013 e 2016

\begin{tabular}{l|l|l}
\hline Região & 2013 & 2016 \\
\hline Total & -0.18 & -0.20 \\
\hline Norte & 0.33 & 0.38 \\
\hline Nordeste & 0.13 & 0.20 \\
\hline Sudeste & -0.35 & -0.40 \\
\hline Sul & -0.23 & -0.21 \\
\hline Centro-Oeste & -0.15 & -0.23 \\
\hline \multicolumn{2}{|c}{ Fonte: Resultado da Pesquisa. }
\end{tabular}

\section{Considerações Finais}

A realização deste estudo possibilitou ver a importância do FPM para a composição da integralidade das receitas dos municípios de pequeno porte, principalmente para os de menor desenvolvimento. Ainda que a dependência destes varie de região para região, bem como o IFDM é variável, todo recurso destinado para que estes realizem seus deveres constitucionais têm sua relevância.

O pacto federativo da $\mathrm{CF} / 88$ repassou responsabilidades que anteriormente não existiam ou que eram de outros entes, ampliou o repasse de recursos da União, e conferiu maior autonomia fiscal para que os municípios passassem a decidir sobre sua própria tributação e, assim, definir os rumos da arrecadação. Mas, diversos são os fatores que dificultam essa mudança, e para municípios de pequeno porte, as instabilidades no processo arrecadatório próprio são ainda maiores.

A respeito da hipótese, tem-se que, ao visualizar a integralidade dos municípios, ela é verdadeira, posto que quanto maior a dependência, menor o desenvolvimento, e vice-versa. Porém, quando se subdivide esta relação entre as regiões, o Norte e o Nordeste apontam para 
uma relação positiva, em maior conformidade com a relação trazida pelos municípios maiores de 20 mil habitantes quando se ampliou os recursos destinados a eles e se atingiu um maior índice de desenvolvimento ao longo dos anos (Tabela 1).

Assim, este artigo é uma introdução a uma análise mais complexa do sistema de transferências de receitas entre os entes federados e os objetivos de diminuição das desigualdades horizontais e verticais, seja na receita ou no desenvolvimento socioeconômico.

\section{Referências}

ABRUCIO, Fernando Luiz; COUTO, Cláudio Gonçalves. A redefinição do papel do Estado no âmbito local. São Paulo em Perspectiva. São Paulo, v. 10, n.3, p.40-47, Jul./Set.1996.

AFFONSO, J. ROBERTO. Brasil, um caso à parte. XVI. Regional Seminar of Fiscal Policy. Santiago do Chile: Cepal/Ilpes, janeiro, 2004. Disponível em: https://www.cepal.org/ilpes/noticias/ paginas/6/13526/robertoafonso.pdf. Acesso em 09 abr. 2019.

ARRETCHE, Marta. Estado federativo e políticas sociais. Rio de Janeiro: Revan, 2000.

ARRETCHE, Marta. Quem taxa e quem gasta: a barganha federativa na federação brasileira. Revista de Sociologia Política, Curitiba: UFPR, n.24, p.69-85, jun. 2005.

BRASIL. Constituição (1988). Constituição da República Federativa do Brasil. Brasília, DF: Senado, 1988.

BOVO, José Murai. Gastos sociais dos municípios e desequilíbrio financeiro. Revista de Administração Pública. Rio de Janeiro, v.35, n. 1, p. 93-117, jan./fev. 2001.

CARVALHO, Cícero Péricles de Oliveira. O Desenvolvimento da Região Nordeste nos Anos Pós-Sudene (2000-2016). Revista Paranaense de Desenvolvimento. Instituto Paranaense de Desenvolvimento Econômico e Social, n²134, jan-jul, 2018.

CASTRO, José Nilo de. Direito Municipal Positivo. 6.ed. rev. atual. Belo Horizonte: Edit. Del Rey, 2006.

COELHO, Dulce Maria Alves da Rocha. Federalismo fiscal no Brasil: Uma análise do Fundo de Participação dos Municípios. 2007. 67 f. Monografia (Especialização) - Curso de Especialização em Orçamento Público, Tribunal de Contas da União e da Câmara dos Deputados, Brasília, 2007.

FARINA, Milton Carlos; GOUVÊA, Maria Aparecida; VARELA, Patricia Siqueira. Transferências Constitucionais e Receitas Tributárias Versus Desempenho Econômico e Social de Alguns Municípios do Estado de São Paulo. In: SEMEAD - SEMINÁRIOS EM ADMINISTRAÇÃO FEA-USP, 10, 2007, São Paulo - SP. Disponível em: <http://sistema.semead.com.br/10semead/sistema/resultado/trabalhosPDF/224. pdf>. Acesso em: 10 abr. 2019.

FLEURY, S. (org.). Democracia, descentralização e desenvolvimento: Brasil e Espanha. Rio de Janeiro: FGV, 2006.

HERMANN, Jennifer. Auge e Declínio do Modelo de Crescimento com Endividamento: O II PND e a Crise da Dívida Externa (1974-1984). In GIAMBIAGI, F; VILLELA, A.; CASTRO, L.; HERMANN, E (org.). Economia Brasileira Contemporânea. Rio de Janeiro: Campus, 2011.

HOFMEISTER, Wilhelm e CARNEIRO, José Murilo Brasiliense (orgs.). Federalismo na Alemanha e no Brasil. São Paulo: Fundação Konrad Adenauer, abr.2001, v.I, n.22. 
IBGE -INSTITUTO BRASILEIRO DE GEOGRAFIA E ESTATÍSTICA. Rendimento de todas as fontes 2017. 2017. Disponível em:< https://agenciadenoticias.ibge.gov.br/media/com_mediaibge/arquivos/ acfb1a9112a9eceedc4ea612d5aaf848.pdf>. Acesso em abr. 2019.

IBGE -INSTITUTO BRASILEIRO DE GEOGRAFIA E ESTATÍSTICA. Nota técnica: estimativa da população dos municípios brasileiros com data de referência em 1o de julho de 2014. Disponível em: https://ww2.ibge.gov.br/home/presidencia/noticias/pdf/analise_estimativas_2014.pdf. Acesso em 25 abr. 2019.

MENDES, Marcos; MIRANDA, Rogério Boueri; COSSIO, Fernando Blanco. Transferências intergovernamentais no Brasil: diagnóstico e proposta de reforma. Texto para Discussão 40. Brasília: Consultoria Legislativa do Senado Federal, abr. 2008.

MENDONÇA, Fernanda de Freitas et al. Participação dos municípios de pequeno porte no Projeto Mais Médicos para o Brasil na macrorregião norte do Paraná. Ciência \& Saúde Coletiva, [s.l.], v. 21, n. 9 , p.2907-2915, set. 2016. FapUNIFESP (SciELO). http://dx.doi.org/10.1590/1413-81232015219.18302016. Disponível em: <http://www.scielo.br/pdf/csc/v21n9/1413-8123-csc-21-09-2907.pdf>. Acesso em: 09 abr. 2019.

ORAIR, Rodrigo Octávio; ALENCAR, André Amorim. Esforço fiscal dos municípios: indicadores de condicionalidade para o sistema de transferências intergovernamentais. Finanças Públicas, Brasília, DF, 2010. Disponível em: <http://www.tesouro.fazenda.gov.br/documents/10180/137713/Premio2010_ Tema_4_1.pdf>. Acesso em: 09 abr. 2019.

PASSOS, C.; NASCIMENTO, J. Fundo de Participação dos Municípios na Composição das Receitas: um estudo sobre dependência dos municípios piauienses nos anos2013 a 2016. Anais... XXV Congresso Brasileiro de Custos - Vitória, ES, Brasil, 12 a 14 de novembro de 2018.

RESENDE, F (org.). Desafios do federalismo fiscal. Rio de Janeiro: FGV, 2007.

SALLUM JR., Brasilio; KUGELMAS, Eduardo. O Leviathan declinante: a crise brasileira dos anos 80. Estud. av., São Paulo, v. 5, n. 13, p. 145-159, Dez. 1991 . Disponível em: <http://www.scielo.br/scielo. php?script=sci_arttext\&pid=S0103-40141991000300009\&lng=en\&nrm=iso>. Acesso em: 11 Abr. 2019. http://dx.doi.org/10.1590/S0103-40141991000300009.

SANTOS, Ângela Moulin Simões Penalva. Município, descentralização e território. Rio de Janeiro: Forense, 2008.

SANTOS, Ângela Moulin Simões Penalva. Autonomia municipal no contexto federativo brasileiro. Revista Paranaense de Desenvolvimento. Instituto Paranaense de Desenvolvimento Econômico e Social, nº 120, jan-jul, 2011. 